\title{
Evaluation of Thromboprophylaxis Practice in Hospitalized Patients in the Medical Department of Saint Jean de Dieu Hospital of Thies, Senegal
}

\author{
Désiré Alain Affangla ${ }^{1,2 *}$, Korko Sélalom Lynda Adomayakpor ${ }^{1}$, Stéphanie Akanni², \\ Jean-Michel Amath Dione ${ }^{1}$, Hugues Elie Elame Ngwa ${ }^{1}$, Djibril Marie Ba ${ }^{2}$, Mohamed Leye ${ }^{2}$, \\ Joao Armindo Da Veiga', Bernard Marcel Diop² \\ ${ }^{1}$ Hôpital Saint Jean de Dieu, Thiès, Sénégal \\ ${ }^{2}$ Unité de Formation et de Recherche des sciences de la santé, Université de Thiès, Thiès, Sénégal \\ Email: *docalaf@gmail.com
}

How to cite this paper: Affangla, D.A., Adomayakpor, K.S.L., Akanni, S., Dione, J.-M.A., Ngwa, H.E.E., Ba, D.M., Leye, M., Da Veiga, J.A. and Diop, B.M. (2020) Evaluation of Thromboprophylaxis Practice in Hospitalized Patients in the Medical Department of Saint Jean De Dieu Hospital of Thies, Senegal. World Journal of Cardiovascular Diseases, 10, 313-318. https://doi.org/10.4236/wjcd.2020.105029

Received: April 20, 2020

Accepted: May 22, 2020

Published: May 25, 2020

Copyright $\odot 2020$ by author(s) and Scientific Research Publishing Inc. This work is licensed under the Creative Commons Attribution International License (CC BY 4.0).

http://creativecommons.org/licenses/by/4.0/

\section{(c) (i) Open Access}

\begin{abstract}
Introduction: Venous thromboembolism disease (VTE) is a common complication of hospitalization. Objective: To assess the practice of thromboprophylaxis in hospitalized patients in the department of medicine. Patients and Methods: It is an observational cross-sectional study conducted from 01 February to 31 March 2019 in the medical departments of the Saint Jean de Dieu Hospital of Thies. All the patients hospitalized with at least 18 years of age were included. The thromboembolic risk was assessed with the Padua score and thromboprophylaxis assessed according to the ACCP 2012 recommendations. Results: One hundred and forty four patients were included. Seventy-one $(49.3 \%)$ were in the high thromboembolic risk category. The most frequently reported risk factors were mobility impairment $(\mathrm{n}=72$; $50 \%)$, age of 70 years or above $(n=35 ; 24.3 \%)$, heart failure $(n=23 ; 16 \%)$, acute infections $(\mathrm{n}=14 ; 9.7 \%)$ and cancers $(\mathrm{n}=13 ; 9.02 \%)$. The prevention of venous thromboembolism was practiced in 25 of the 71 patients with high thromboembolic risk or a rate of $35.2 \%$. Thromboprophylaxis was exclusively drug-based with Enoxaparin. Conclusion: The practice of prophylaxis for VTE was low in the medical departments. Efforts still need to be made to reduce the high rate of thromboembolic complications associated with hospitalization.
\end{abstract}

\section{Keywords}

Venous Thromboembolism Disease, Thromboprophylaxis, Heparin 


\section{Introduction}

Venous thromboembolism (VTE) is a condition in which a blood clot forms most often in the deep veins of the leg, groin or arm (known as deep vein thrombosis, DVT) and travels in the circulation, lodging in the lungs (known as pulmonary embolism, PE). It remains a public health problem in sub-Saharan African countries with prevalence between $2.7 \%$ and 9.12\% [1] [2] [3]. There are several risk factors exposing to this disease. Hospitalization in a health facility is a high-risk transient circumstance for VTE. A better knowledge of these risk factors has led to recommendations for the prevention of venous thromboembolism in risky patients. However, it is clear that thromboprophylaxis remains under practiced [2] [4] [5]. The objective of our study was to assess the practice of thromboprophylaxis in patients hospitalized in the medical departments of the Saint Jean de Dieu Hospital of Thies.

\section{Patients and Methods}

This was an observational cross-sectional study carried out in the medical departments of the Saint Jean de Dieu Hospital of Thies, including the department of internal medicine and the department caring for diabetes and cardio-metabolic diseases (Diabcarmet), over a period of two months (from 01 February 2019 to 31 March 2019). Included were the hospitalized patients of at least 18 years of age. Patients already taking anticoagulants, those admitted for VTE, and patients who did not consent to participate in the study were not included. A survey sheet was made to collect the patient data. Socio-demographic data, duration of hospitalization, diagnostics according to the tenth version of the WHO International Classification of Diseases (ICD10) data was collected. The risk of VTE was assessed based on the Padua score [6] and the thromboprophylaxis prescription assessed according to the ACCP 2012 recommendations. [7]. The data was collected using the ACCESS 2010 software and analyzed using the Epi info 3.5 software version 3.5.4 of 30 July 2012, CDC, Atlanta (USA). The Khi2 comparison test was used for the comparison of proportions and the analysis of variances (ANOVA) test for the comparison of quantitative variable with group qualitative variable after completion of the validity tests. The significance threshold was set at $\mathrm{p} \leq 0.05$.

\section{Results}

We collected data from 144 patients with a mean age of 54 years \pm 14.9 years (extremes of 18 to 93 years). There were 60 women (41.7\%) and 84 men (58.3\%) with a sex ratio $\mathrm{F} / \mathrm{M}$ of 0.71 . The average length of hospitalization was 6 days \pm 4.47 days (extremes of 1 to 28 days). The most common risk factors for VTE were reduced mobility $(\mathrm{n}=72 ; 50 \%)$, age over 70 years $(\mathrm{n}=35 ; 24.3 \%)$, heart failure $(\mathrm{n}=23 ; 16 \%)$, infection $(\mathrm{n}=14 ; 9.7 \%)$ and active cancer $(\mathrm{n}=13 ; 9.02 \%)$ (Figure 1). The estimation of the risk level of VTE according to the Padua score allowed to find 71 patients (49.3\%) with a high thromboembolic risk, or a Padua 


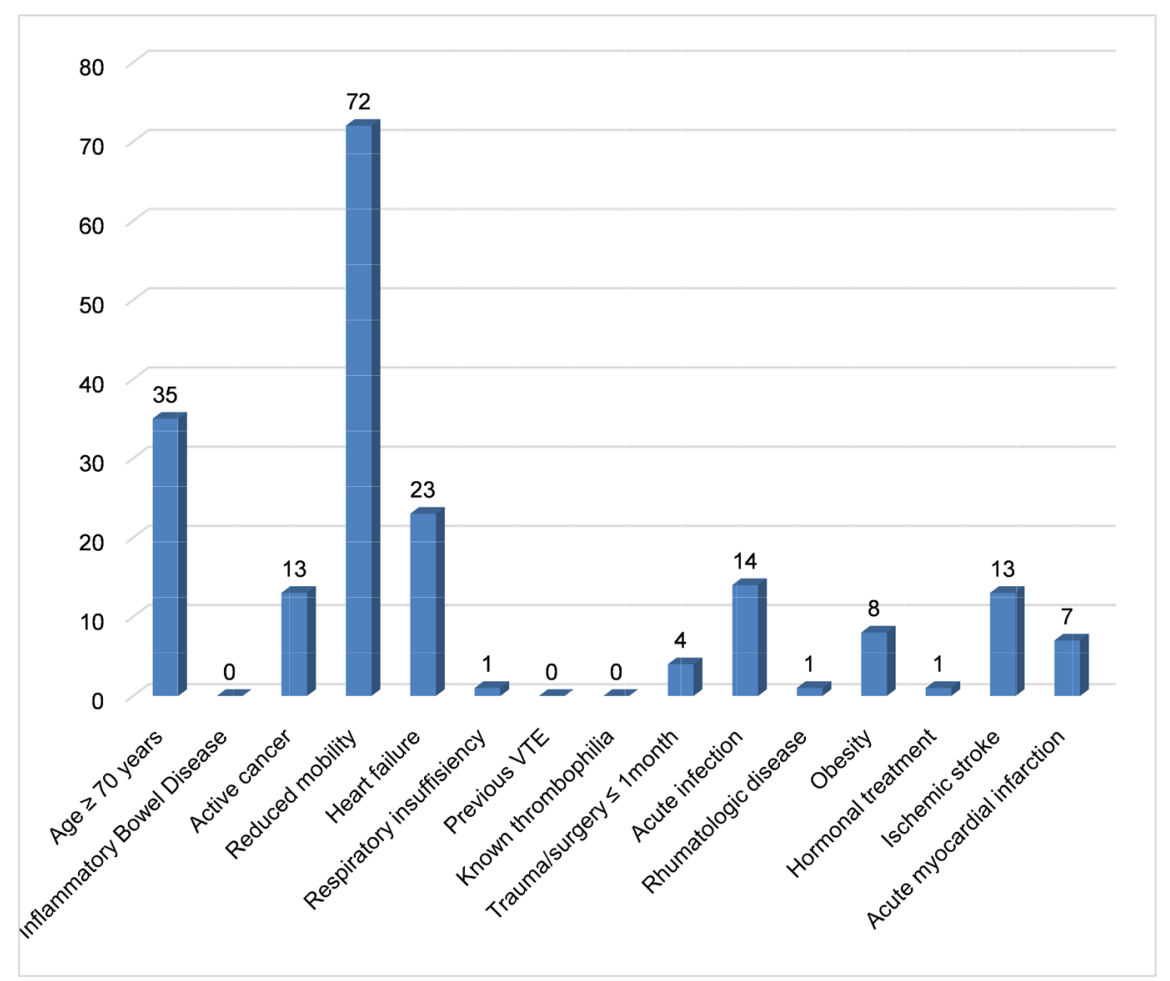

Figure 1. Thromboembolic risk factors of patients according to Padua score.

score higher or equal to 4 against 73 patients (50.7\%) with a low risk or a score lower than 4 (Table 1). Among these high thromboembolic risk patients, 28 (39.4\%) were female and $43(60.6 \%)$ male $(\mathrm{p}=0.7578)$. Two statistically significant risk factors were identified: bed rest of more than three days $(\mathrm{n}=68 ; 96 \%$; $\mathrm{OR}=391$; CI 90\%: $84.34-1813)$ and age over 70 years $(\mathrm{n}=31 ; 46.66 \%$; OR = 0.0748; CI 90\%: $0.0246-0.2274)$. However, obesity was not a statistically significant thromboembolic risk factor ( $\mathrm{OR}=1.23$; IC 90\%: 0.32 - 4.79). Indeed, $67 \mathrm{pa}-$ tients with a Padua score of 4 or more had a body mass index of less than 30 $\mathrm{kg} / \mathrm{m}^{2}$ and 4 patients with a body mass index of more than $30 \mathrm{~kg} / \mathrm{m}^{2}$ had a Padua score of 4 or more.

The repartition of diseases according to ICD 10 in patients at high thromboembolic risk $(\mathrm{n}=71)$, revealed 43 patients $(29.86 \%)$ with circulatory disease including 23 (15.97\%) heart failure, 13 (9\%) stroke and 7 (4.86\%) acute myocardial infarction; 9 patients (6.25\%) with endocrine, nutritional and metabolic disease, 9 patients $(6.25 \%)$ with cancer, 8 patients (5.55\%) with infectious disease. Thromboprophylaxis was adequately prescribed in 25 high-risk patients (35.2\%). While inadequately 46 patients in high-risk patients (64.8\%) did not receive thromboprophylaxis; five patients had contraindications to anticoagulant treatment but mechanical thromboprophylaxis was not prescribed; two patients $(1.38 \%)$ who were at low thromboembolic risk had Enoxaparin-based thromboprophylaxis. Only drug-based thromboprophylaxis was prescribed and no patient had received mechanical thromboprophylaxis prescription and Enoxaparin was used. 
Table 1. Thromboembolic risk of admitted patients.

\begin{tabular}{ccc}
\hline Padua score & Number $(\mathrm{n})$ & Percentage $(\%)$ \\
\hline$\geq 4:$ high risk & 71 & 49.30 \\
$<4$ : low risk & 73 & 50.70 \\
Total & 144 & 100 \\
\hline
\end{tabular}

\section{Discussion}

The mean age of patients in our study was 54 years \pm 14.94 years. Dia et al. [8] found younger patients with an average age of 47 years in similar work in Dakar, while in the Endorse France survey [4] the patients were older with a mean age of 73 years. In the Endorse France study, only patients of 40 years and over were included. Age is a risk factor for VTE and the incidence of venous thromboembolism disease increases with age. Age was found to be a statistically significant risk factor in high thromboembolic risk patients in our work. This result was comparable to that found by Dia et al. in their work [8] where age was also a risk factor in $47 \%$ of patients. A statistically insignificant male predominance was found in our work (58.3\%) as in the Endorse Senegal study [2] (58.7\%) and in the Endorse France study (52.5\%) [4].

The average length of hospitalization was 6 days \pm 4.47 days in our work. These results differ from those found in the Houenassi et al. study in Benin [9] which included patients hospitalized for at least four days. In the Endorse Senegal study [2], 66\% of the patients included had been hospitalized for at least 10 days before the start of the survey. A statistically significant relation between hospitalization duration and thromboembolic risk was found in our work ( $\mathrm{p}=$ 0.00001).

In our study, almost the half (49.3\%) of patients were at high thromboembolic risk. This rate was close to the one found in Tunisia of 46.5\% [10] but lower than Quebec in the work of Lanthier et al. and in the Endorse study in Senegal which found respectively 57.4\% and 57\% [2] [11]. In France, this rate of high thromboembolic risk patients was lower (36.4\%) [4] while in Senegal, Dia and her team found a higher rate of $77 \%$ of patients requiring thromboprophylaxis [8]. These differences could be attributed to the non-similarity of the risk factors of the VTE considered in the methodologies. The risk factors found in our study were reduced mobility (50\%) followed by age above or equal to 70 years $(24.3 \%)$ and heart failure (16\%). Then came acute infections (9.7\%), ischemic stroke and cancer counting for $9.02 \%$, obesity $(5.6 \%)$ and acute myocardial infarction (4.9\%). Finally, respiratory failure, rheumatic diseases and hormonal treatment represented 0.7\%. In his study, Pottier [12] found similar results. Lanthier et al. [11] found as the most important risk factors, the age (77.6\%), followed by reduced mobility (38.8\%) and BMI (24\%). In the study of Dia et al. [8], the risk factors were bed rest (98\%), age over 40 years (47\%) and cancer (20.1\%). Heart failure and respiratory diseases represented respectively $9.3 \%$ and $8.5 \%$. In Tunisia, the Endorse study [10] found a predominance of cardiovascular risk factors 
(40\%) followed by lung infections (36.1\%). No cases of thrombophilia, chronic inflammatory bowel disease or history of venous thromboembolism disease were found while Lanthier in his study had two patients $(1.1 \%)$ with chronic inflammatory bowel disease and $4.4 \%$ with a history of venous thromboembolism disease [11].

In our study, only one out of three (35.2\%) high-risk patients received thromboprophylaxis. These results are lower than those of Lanthier et al. [11] which reported a thromboprophylaxis rate of $83.7 \%$ in Quebec. In Senegal, Dia et al. [8] found in their study in internal medicine department, a thromboprophylaxis rate of $12 \%$ in patients at risk of thromboembolism.

It appears that the rate of thromboprophylaxis varied considerably between countries and facilities. Thromboprophylaxis was exclusively drug-based and only Enoxaparin was prescribed. In contrast, 2 patients with a low thromboembolic risk received Enoxaparin at a preventive dose, when this was not indicated. Pottier found in an internal medicine department that $42 \%$ of patients had heparin-based thromboprophylaxis, of which $38 \%$ rightly and $4 \%$ not because they did not require it [12]. In our study, we had five cases of contraindication to anticoagulation treatment or $7.04 \%$. This is comparable to the Endorse Senegal study where the frequency of contraindication was $7.9 \%$ [2].

\section{Conclusion}

Thromboprophylaxis practice is low practiced in hospitalized patients in medical departments as recommended. Efforts must be made to ensure a better security of our patients from VTE.

\section{Conflict of Interest}

The authors declare that they have no conflict of interest related to this work.

\section{Limitation}

The limitation of this study was the small sample size.

\section{References}

[1] Delluc, A., Le Ven, F., Mottier, D. and Le Gal, G. (2012) Epidémiologie et facteurs de risque de la maladie veineuse thromboembolique. Revue des Maladies Respiratoires, 29, 254-266. https://doi.org/10.1016/j.rmr.2011.12.001

[2] Bâ, S.A., Badiane, S.B., Diop, S.N., et al. (2011) A Cross-Sectional Evaluation of Venous Thromboembolism Risk and Use of Venous Thromboembolism Prophylaxis in Hospitalized Patients in Senegal. Archives of Cardiovascular Diseases, 104, 493-501. https://doi.org/10.1016/j.acvd.2011.05.007

[3] Damorou, F., Baragou, S., Pio, M., et al. (2014) Morbidité et mortalité hospitalière des maladies cardiovasculaires en milieu tropical: exemple d'un centre hospitalier à Lomé (Togo). Pan African Medical Journal, 17, 62. https://doi.org/10.11604/pamj.2014.17.62.2237

[4] Bergmann, J.-F., Lloret-Linares, C., Rami, A., et al. (2011) Risque thromboemboli- 
que veineux et pratique de prévention hospitalière: Résultats obtenus en France de l'étude internationale ENDORSE. Presse Médicale, 40, e528-e537. https://doi.org/10.1016/j.lpm.2011.06.023

[5] Cohen, A., Tapson, V., Bergmann, J., et al. (2008) Venous Thromboembolism Risk and Prophylaxis in the Acute Hospital Care Setting (ENDORSE Study): A Multinational Cross-Sectional Study. The Lancet, 371, 387-394.

https://doi.org/10.1016/S0140-6736(08)60202-0

[6] Barbar, S., Noventa, F., Rossetto, V., et al. (2010) A Risk Assessment Model for the Identification of Hospitalized Medical Patients at Risk for Venous Thromboembolism: The Padua Prediction Score. Journal of Thrombosis and Haemostasis, 8 , 2450-2457. https://doi.org/10.1111/j.1538-7836.2010.04044.x

[7] Guyatt, G.H., Akl, E.A., Crowther, M., et al. (2012) American College of Chest Physicians Antithrombotic Therapy and Prevention of Thrombosis Panel Executive summary: Antithrombotic Therapy and Prevention, 9th Ed. American College of Chest Physicians Evidence-Based Clinical Practice Guidelines. Chest, 141, 7S-S47. https://doi.org/10.1378/chest.141.4.1129a

[8] Dia, D.G., Fall, S., Dia, A.D., et al. (2015) Evaluation du risque thromboembolique veineux et pratique de la thromboprophylaxie en médecine interne. The Pan African Medical Journal, 22, 386. https://doi.org/10.11604/pamj.2015.22.386.7988

[9] Houénassi, M.D., Tchabi, Y., Akindès-DossouYovo, R., et al. (2009) Prevention of Venous Thromboembolism among Inpatients at Cotonou Teaching Hospital, Benin. Archives of Cardiovascular Diseases, 102, 5-9. https://doi.org/10.1016/j.acvd.2008.10.009

[10] Jerbi, Z., Houman, M.H., Ghedira, H., et al. (2011) Venous Thromboembolism Risk and Prophylaxis in the Acute Hospital Care Setting-Results of the Endorse Study in Tunisia. La Tunisie Médicale, 89, 784-789.

[11] Lanthier, L., Béchard, D., Viens, D., et al. (2011) Evaluation of Thromboprophylaxis in Patients Hospitalized in a Tertiary Care Center: An Applicable Model of Clinical Practice Evaluation. Revision of 320 Cases. Journal des Maladies Vasculaires, 36, 3-8. https://doi.org/10.1016/j.jmv.2010.10.005

[12] Pottier, P., Planchon, B., Pistorius, M.-A., et al. (2002) Facteurs de risque de la maladie thromboembolique veineuse chez des malades hospitalisés en médecine interne: Une enquête cas-témoins sur 150 patients. La Revue de Médecine Interne, 23, 910-918. https://doi.org/10.1016/S0248-8663(02)00686-0 